\title{
Identification and Stimulation by Serotonin of Intrinsic Sensory Neurons of the Submucosal Plexus of the Guinea Pig Gut: Activity-induced Expression of Fos Immunoreactivity
}

\author{
A. L. Kirchgessner, H. Tamir, and M. D. Gershon \\ Department of Anatomy and Cell Biology, Columbia University College of Physicians and Surgeons, New York, \\ New York 10032
}

The bowel is the only organ of the body in which neural reflexes can be elicited in the absence of input from the brain or spinal cord. This activity is mediated by the enteric nervous system (ENS), which contains primary afferent neurons. Experiments were carried out to locate the primary afferent neurons of the ENS. Two types of stimulation were used to activate neurons in the wall of the gut in vitro: exposure of the mucosa to cholera toxin or delivery of pressure to the mucosal surface with puffs of $\mathrm{N}_{2}$ from a micropipette. Neurons that became active in response to these stimuli were identified by demonstrating the intranuclear immunoreactivity of Fos, the product of the c-fos protooncogene. No Fos immunoreactivity could be detected in the absence of stimulation; however, application of cholera toxin and puffs of $\mathrm{N}_{2}$ each induced the appearance of Fos immunoreactivity in neurons in both the submucosal and myenteric plexuses. With either stimulus, the induction of Fos immunoreactivity was antagonized by TTX and therefore depended on neuronal activity. The appearance of Fos immunoreactivity could also be prevented by the $5-\mathrm{HT}_{1 \mathrm{P}}$ receptor antagonist $\mathrm{N}$-acetyl-5-hydroxytryptophyl-5-hydroxytryptophan amide. In contrast, the stimulus-induced expression of Fos immunoreactivity was inhibited, but not abolished, by hexamethonium, which limited the spread of activation within the submucosal plexus and completely prevented expression of Fos immunoreactivity by myenteric neurons in response to mucosal puffs of $\mathbf{N}_{2}$. FluoroGold was injected into single ganglia of the myenteric plexus in order to identify submucosal neurons with myenteric projections. Submucosal neurons in which Fos immunoreactivity was induced by the stimuli were doubly labeled by FluoroGold. A subset of the submucosal, but not myenteric, neurons that expressed Fos immunoreactivity was doubly labeled by antibodies to calbindin. Submucosal calbindin-immunoreactive neurons were found to contain substance $P$ immunoreactivity and could also be immunostained by anti-idiotypic antibodies that react with $5-\mathrm{HT}_{1 \mathrm{P}}$

Received Apr. 24, 1991; revised Aug. 22, 1991; accepted Aug. 26, 1991.

We thank Dr. Allan Basbaum for his generous contribution of antibodies to Fos and Dr. Sylvia Christakos for her generous contribution of antibodies to calbindin. This work was supported by NIH Grants NS 27645, NS 12969, NS 15547 , and NIMH 337575 . A.L.K. was also supported by a feasibility grant from the American Diabetes Association.

Correspondence should be addressed to Dr. Annette Kirchgessner, Department of Anatomy and Cell Biology, Columbia University, College of P \& S, 630 West 168th Street, New York, NY 10032.

Copyright (C) 1992 Society for Neuroscience 0270-6474/92/120235-14\$05.00/0 receptors. A subset of dynorphin ${ }_{1-8}$-immunoreactive submucosal neurons (which are known to costore vasoactive intestinal peptide and to be secretomotor in function) expressed nuclear Fos immunoreactivity in response to cholera toxin, but not puffs of $\mathbf{N}_{\mathbf{2}}$. These data suggest that intrinsic primary afferent neurons are located in the submucosal plexus, project to the myenteric plexus, and are activated by $5-\mathrm{HT}$ acting on the $5-\mathrm{HT}_{1 \mathrm{p}}$ receptor subtype. These neurons are probably cholinergic and costore calbindin and substance $P$.

The gut is the only organ that displays reflex activity when isolated from the brain and spinal cord (Gershon, 1981; Furness and Costa, 1987). This activity, the peristaltic reflex (Kosterlitz and Lees, 1964), was first noted by Bayliss and Starling $(1899,1900)$ and consists of contraction oral and relaxation anal to a site where pressure is applied to the gastrointestinal mucosa. Since the peristaltic reflex can be evoked in vitro (Trendelenburg, 1917), it is mediated by neurons present within the wall of the gut. These observations indicate that the enteric nervous system (ENS) must contain intrinsic primary afferent neurons and interneurons, as well as the sensory receptors and motor neurons needed to evoke the reflex behavior.

The sensory receptors that give rise to the peristaltic reflex have been demonstrated to be located in the intestinal mucosa (Bülbring and Lin, 1958). The primary afferent neurons have not yet been definitively identified. These cells were postulated by Bülbring et al. (1958) to be located in the submucosal plexus because a subset of submucosal neurons were found that are pseudounipolar or bipolar in shape. The idea that intrinsic primary afferent neurons exist in the submucosal plexus has received support from the observations that submucosal ganglia project to both the mucosa and the myenteric plexus (Kirchgessner and Gershon, 1988), that some submucosal neurons share surface antigens with sensory neurons in dorsal root ganglia (Kirchgessner et al., 1988), and that a subset of submucosal neurons appears to receive no synaptic input (Surprenant, 1984). This latter subset is substance $P$ immunoreactive (Bornstein et al., 1989). Recently, however, it has been proposed that the intrinsic primary afferent neurons of the ENS are not submucosal, but myenteric (Iyer et al., 1988; Furness et al., 1990; Hendriks et al., 1990). This contrary hypothesis is based on immunocytochemical and electrophysiological studies. The majority of neurons classified physiologically as $\mathrm{AH} /$ type 2, which were originally thought to receive little or no synaptic input 
(Hirst et al., 1974), are reported to be calbindin immunoreactive (Iyer et al., 1988). Calbindin-immunoreactive neurons in the myenteric plexus project to the mucosa and to other myenteric neurons (Furness et al., 1990). These properties are presumed to be those that should be displayed by primary sensory neurons. Some of these presumptions are controversial. It is now clear that myenteric AH/type 2 neurons are not devoid of synaptic input, as might be expected of sensory neurons, but actually are heavily innervated (Erde et al., 1985; Wade et al., 1991). Moreover, the 1:1 relationship between calbindin immunoreactivity and the electrophysiological classification of myenteric neurons needs to be confirmed. Clearly, it is conceivable that subsets of enteric sensory neurons could be located in each of the enteric plexuses.

The cvidence favoring the localization of intrinsic sensory neurons in either plexus is indirect. In order to determine which neurons of the ENS become active following the application of a stimulus capable of eliciting the peristaltic reflex, the immunoreactivity of the protein, Fos, encoded by the $c$-fos protooncogene was studied. The Fos protein has been proposed as a nuclear "third messenger" that transduces extracellular signals to long-term changes in cell function by regulating the expression of responsive genes (Curran and Morgan, 1985). Increased expression of this protein has been observed to occur in the nucleus of neurons of the brain and spinal cord that have been activated by a variety of stimuli (Hunt et al., 1987; Morgan et al., 1987; Sagar et al., 1988). The immunocytochemical demonstration of Fos immunoreactivity has been shown to be a useful marker of neuronal "activity" that demonstrates functionally related neural pathways (Menétrey et al., 1989; Presley et al., 1990). The rclationship betwecn nuclcar immunoreactivity of Fos in enteric neurons and their physiological activation was first assessed by studying the effect of mucosal applications of cholera toxin (in the presence or absence of TTX) on $c$-fos expression. Although the mucosal application of cholera toxin is not a physiological stimulus, it is known to powerfully activate peristalsis (Cassuto et al., 1982, 1983) and has previously been demonstrated, by measuring cytochrome oxidase activity, to stimulate both submucosal and myenteric neurons (Gershon et al., 1989b). Subsequently, as a more physiological stimulus, pressure was applied to the mucosal surface of the bowel by directing puffs of $\mathrm{N}_{2}$ at it from the tip of a micropipette in order to activate mucosal sensory receptors. Application of pressure to the mucosal surface of the bowel is also known to stimulate the peristaltic reflex. Cholera toxin was selected to serve as an example of a massive diffuse stimulus, which increases intestinal secretion as wcll as motility. In contrast, the application of pressure with slight puffs of $\mathrm{N}_{2}$ was chosen as an example of a minimal and highly localized stimulus that would increase motility without stimulating secretion at the same time. Neurons of the submucosal plexus that have myenteric projections were simultaneously identified by retrograde axonal transport of FluoroGold. These studies were combined with the visualization of antiidiotypic antibodies that recognize 5-HT receptors (Tamir et al., 1991) and calbindin, substance P, neuropeptide Y (NPY), calcitonin gene-related peptide (CGRP), and dynorphin 1-8 $_{\text {(DYN) }}$ immunoreactivities. Application of cholera toxin and mucosal deformation with puffs of $\mathrm{N}_{2}$ were each found to induce Fos immunoreactivity in a subset of submucosal and myenteric neurons. Affected neurons of the submucosal plexus were observed to project to myenteric ganglia. These cells also expressed 5-HT receptor, calbindin, and substance $P$ immunoreactivities.

\section{Materials and Methods}

Tissue preparation for injection of myenteric ganglia. The method used for identifying those submucosal neurons that project to the myenteric plexus was similar to that described previously (Kirchgessner and Gershon, 1988). Male guinea pigs $(\cong 350 \mathrm{gm})$ were stunned by a blow to the head and exsanguinated. This procedure has been approved by the Animal Use and Care Committee of Columbia University. Segments of small intestine (caudal to the ligament of Treitz) were removed and opened along the mesenteric border, and the resulting rectangular sheet of intestine was pinned flat. The mucosa was gradually scraped away to reveal the submucosal and myenteric layers of the intestinal wall For those experiments in which the mucosa was to be stimulated, only a small area of the mucosa $\left(\cong 2 \mathrm{~mm}^{2}\right)$ adjacent to the stimulated region was removed in order to create a window through which the enteric plexuses could be visualized.

A segment of dissected tissue containing the submucosa and muscularis externa (or the entire gut wall with a mucosal window) was stretched flat in an organ chamber $(36 \mathrm{~mm} \times 44 \mathrm{~mm}$ ) filled with oxygenated Krebs' solution. For injections of myenteric ganglia, these preparations were mounted serosal side up. The organ chamber was then placed on the stage of an inverted microscope, and the tissue was superfused with oxygenated Krebs' solution $(10-15 \mathrm{ml} / \mathrm{min})$ at $37^{\circ} \mathrm{C}$. In order to paralyze smooth muscle, nifedipine $(1.0 \mu \mathrm{M})$ was added to the superfusing medium. The myenteric and submucosal plexuses were visualized using Hoffman modulation contrast optics at a final magnification of $40 \times$. Injections were made with glass micropipettes that were positioned under visual guidance with a micromanipulator (Narishige, Tokyo, Japan). The micropipettes were broken back to a tip size of 8-12 $\mu \mathrm{m}$. A single ganglion (located in the center of the tissue) was injected in each preparation. In preparations with a mucosal window, the injected ganglion was located at one edge of the window as close as possible to the stimulated region.

FluoroGold (4\%; Fluorochrome Inc.) was employed for tracing neuronal projections to the myenteric plexus using retrograde transport. The tracer was injected by pressure ( $8 \mathrm{psi}$ ) into a myenteric ganglion with $100 \mathrm{msec}$ pulses of $\mathrm{N}_{2}$ at a frequency of $1.0 \mathrm{~Hz}$ for $1.5 \mathrm{~min}$ as described previously (Kirchgessner and Gershon, 1988). Three hours were allotted for retrograde transport in vitro. When substance $\mathrm{P}$ immunoreactivity was to be demonstrated, incubation was continued for an additional $2-3 \mathrm{hr}$ in the presence of colchicine $(10 \mu \mathrm{M})$. Injected preparations were transferred to another chamber, pinned flat, and fixed for $1-2 \mathrm{hr}$ with $4 \%(\mathrm{w} / \mathrm{v})$ formaldehyde (from paraformaldehyde) in 0.1 $\mathrm{M}$ phosphate buffer (pH 7.4). Following fixation, the flat intestinal preparations were washed with phosphate-buffered saline (PBS; pH 7.4) and subjected to further dissection. Two whole-mounts, one containing the submucosal and the other the myenteric plexus, were prepared (Kirchgessner and Gershon, 1988). These preparations were mounted and coverslipped on glass slides in a nonfluorescent mounting medium (29:1 glycerin:PBS buffer, containing $1 \mathrm{mg} / \mathrm{ml} p$-phenylenediamine; Ju et al., 1989). The fluorescence of FluoroGold was visualized by vertical fluorescence microscopy using the " $A$ " cube (excitation light, 340-380 $\mathrm{nm}$; dichroic mirror cutoff, $400 \mathrm{~nm}$; suppression filter, $340 \mathrm{~nm}$ ) of a Leilz fluorescence microscope.

Stimulation of mucosal sensory receptors. In order to study the effects of mucosal deformation on expression of Fos immunoreactivity, segments of guinea pig ileum ( $8 \mathrm{~cm}$ in length) were opened, stretched flat (mucosal side up), and incubated in oxygenated Krebs' solution at $37^{\circ} \mathrm{C}$. Puffs of $\mathrm{N}_{2}$ were then delivered from the tip of a micropipette $(20 \mu \mathrm{m}$ tip diameter; $1.5 \mathrm{~Hz}, 10 \mathrm{msec}, 10.0 \mathrm{psi}$ ) with a Picospritzer $\mathrm{m}_{\mathrm{S}}$ to the mucosal surface of the gut. The tip was positioned $2 \mathrm{~cm}$ from the intestinal lining. The puffs were applied for $30 \mathrm{~min}$ to $1 \mathrm{hr}$ in the presence or absence of drugs [tetrodotoxin $(1.0 \mu \mathrm{M})$, hexamethonium $(10.0 \mu \mathrm{M})$, $\mathrm{N}$-acetyl-5-hydroxytryptophyl-5-hydroxytryptophan (5-HTP-DP; 10.0 $\mu \mathrm{M})]$, and the tissue was allowed to incubate for an additional $2 \mathrm{hr}$. Control tissues were pinned flat and treated in the same way as the stimulated preparations except that $\mathrm{N}_{2}$ bursts were omitted. Preliminary experiments revealed that little activation of Fos expression occurred when the stimuli were applied for $30 \mathrm{~min}$ but that good activation could be detected when the stimuli were applied for $1 \mathrm{hr}$. All subsequent experiments, therefore, were carried out with a $1 \mathrm{hr}$ stimulus. When application of mucosal pressure was combined with retrograde tracing to analyze Fos immunoreactivity in submucosal neurons with myenteric projections, a window was cut in the mucosa after the application of stimuli and myenteric ganglia were injected with FluoroGold as de- 

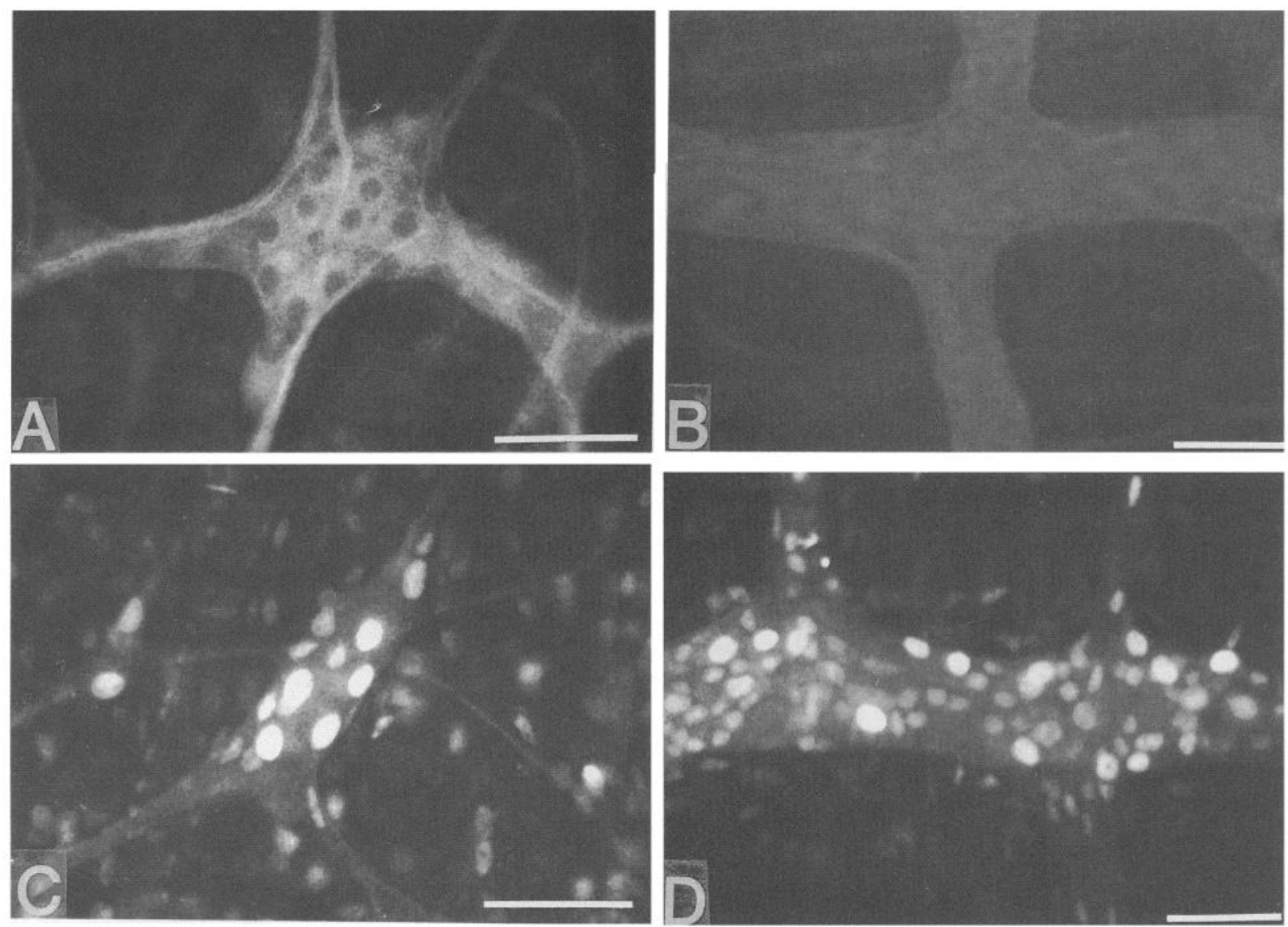

Figure 1. Intraluminal application of cholera toxin induces the expression of Fos in the nuclei of neurons of both submucosal and myenteric ganglia. $A$ and $B$, Control preparations. No Fos immunoreactivity can be seen in nuclei of either submucosal $(A)$ or myenteric ganglia $(B)$ in the absence of stimulation. $C$ and $D$, Cholera toxin. The nuclei of many neurons in both submucosal $(C)$ and myenteric $(D)$ ganglia are Fos immunoreactive. Scale bars, $50 \mu \mathrm{m}$.

scribed above. Cutting the mucosal window did not cause Fos immunoreactivity to appear in the nuclei of enteric neurons.

The effects of mucosal application of cholera toxin on Fos immunoreactivity were also investigated. In order to apply cholera toxin to the mucosal surface of the gut, sacs of guinea pig small intestine $(\cong 3.0$ $\mathrm{cm}$ in length) were filled with $250 \mu \mathrm{l}$ of Krebs' solution containing 10 $\mu \mathrm{g}$ of cholera toxin. Control sacs were filled with a similar solution from which cholera toxin was omitted. Alternatively, sacs were filled with Krebs' solution containing both cholera toxin $(10 \mu \mathrm{g})$ and tetrodotoxin $(1.0 \mu \mathrm{M})$ to prevent activation of neurons in the intestinal wall. The sacs were then tied at both ends with silk threads and incubated in oxygenated Krebs' solution at $37^{\circ} \mathrm{C}$ for $3 \mathrm{hr}$. In additional experiments, hexamethonium $(10.0 \mu \mathrm{M})$ or 5-HTP-DP $(10.0 \mu \mathrm{M})$ was added, both to the cholera toxin-containing solution inside the sac and to the external medium. Hexamethonium was used to block nicotinic ganglionic transmission, and 5-HTP-DP was employed to antagonize effects of 5- $\mathrm{HT}_{\mathrm{IP}}$ receptors (Mawe et al., 1986). In order to inhibit all types of synaptic transmission, some preparations were incubated in a modified, low$\mathrm{Ca}^{2+}(0.5 \mathrm{~mm}) / \mathrm{high}-\mathrm{Mg}^{2+}(16 \mathrm{~mm}) \mathrm{Krebs}$ solution. At the end of the incubation period, the sacs were opened along the mesenteric border, pinned flat mucosal side up, and fixed (as above) for $3 \mathrm{hr}$ at room temperature.

Immunocytochemistry. For immunocytochemistry, whole-mounts were first incubated in $4 \%(\mathrm{v} / \mathrm{v})$ normal horse serum in PBS for $30 \mathrm{~min}$. Horse serum (4\%) and $1.0 \%$ Triton X-100 (to enhance penetration of the immunoreagents) were added to all subsequent solutions containing antisera. The preparations were then exposed for $24-48 \mathrm{hr}$ at $4^{\circ} \mathrm{C}$ to one or more of the primary antibodies listed in Table 1. After washing with PBS, the preparations were incubated with biotinylated speciesspecific secondary antibodies, which included goat anti-rabbit IgG, goat anti-rat IgG, and rabbit anti-goat IgG (Kirkegaard and Perry), diluted
1:400, for $3 \mathrm{hr}$ at room temperature. The whole-mounts were washed again in PBS and then incubated for $1 \mathrm{hr}$ with avidin conjugated to fluorescein isothiocyanate (FITC; diluted 1:200; Vector Labs.). After washing with PBS, the tissues were coverslipped in nonfluorescent medium (as for the visualization of FluoroGold described above). Sites of immunoreactivity were visualized by vertical fluorescence microscopy using the Leitz " $\mathrm{L}_{2}$ " filter cube (exciting filter BP 450-490; dichroic mirror RKP 510; barrier filter BP 525/20). When double label immunocytochemistry was performed, one antigen was visualized with a biotinylated secondary antibody and avidin-FITC and the other antigen was localized with a species-specific secondary antibody coupled to tetramethylrhodamine isothiocyanate (TRITC; Kirkegaard and Perry) diluted 1:80. TRITC fluorescence was visualized using a Leitz " $\mathrm{N}_{2}$ " filter cube (exciting filter BP 530-560; dichroic mirror RKP 580; barrier filter LP 580). There is no cross-detection between the FITC (" $L_{2}$ ")and TRITC (" $\mathrm{N}_{2}$ ")-selective dichroic mirror/filter cubes.

\section{Results}

\section{Effects of intraluminal cholera toxin on the expression of}

Fos by enteric neurons

Expression of Fos immunoreactivity was first examined in preparations of guinea pig small intestine that were fixed immediately after dissection from the animals. No Fos immunoreactivity could be detected in the nuclei of neurons of either submucosal or myenteric ganglia (Fig. $1 A, B$ ). Sacs of gut were then prepared and incubated in vitro for $3 \mathrm{hr}$. Again, when the sacs were filled with Krebs' solution alone, no Fos immunoreactivity could be detected in the nuclei of submucosal or 


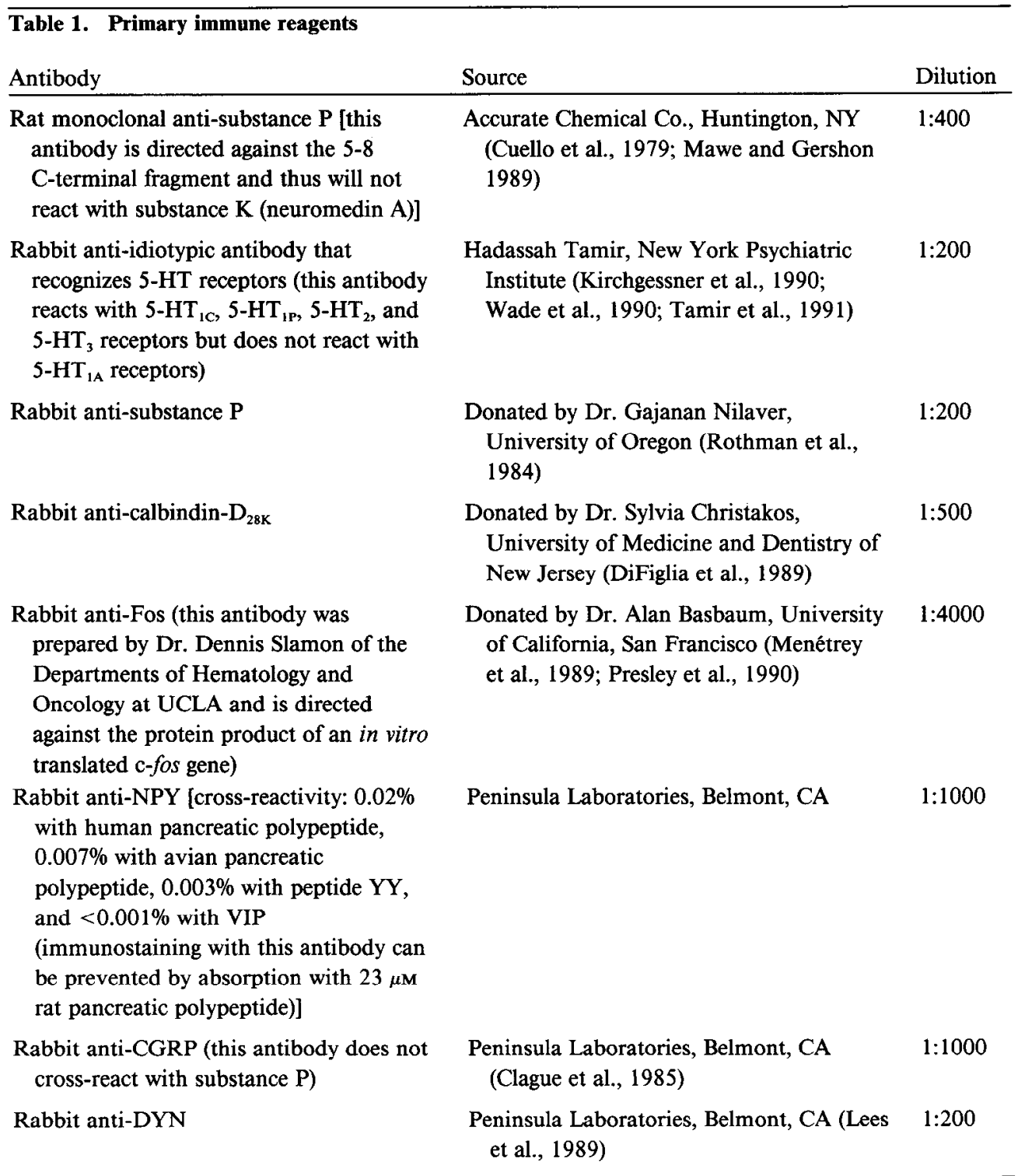

myenteric neurons. In contrast, when the lumen of the sacs contained cholera toxin, neurons that expressed Fos immunoreactivity were abundant in both myenteric and submucosal ganglia (Figs. $1 C, D ; 2$ ). In order to test the hypothesis that the induction of Fos immunoreactivity by cholera toxin was related to an increase in the electrical activity of stimulated neurons, TTX $(1.0 \mu \mathrm{M})$ was added to the solution inside the sacs. TTX antagonized the ability of intraluminal cholera toxin to induce the expression of Fos immunoreactivity. In the submucosal plexus, nuclear expression of Fos immunoreactivity was very much reduced by TTX (Fig. 2), although a small number of Fos-immunoreactive neurons were still found, especially near the ties at the ends of sacs. In the myenteric plexus, however, no Fos-immunoreactive myenteric neurons were seen at all when TTX was added to the sacs (Fig. $3 A$ ). Both the nicotinic receptor antagonist hexamethonium and the $5-\mathrm{HT}_{1 \mathrm{P}}$ receptor antagonist 5-HTP-DP (10 $\mu \mathrm{M}$; present both inside the sac and in the solution in which the sac was suspended) also antagonized the cholera toxin-induced increase in expression of Fos immunoreactivity in enteric neurons (Fig. 2). Each of these compounds, however, was significantly less effective than TTX (Fig. 3B). In order to determine the role of synaptic transmission in the Fosinducing action of cholera toxin, sacs were incubated in media that had a low concentration of $\mathrm{Ca}^{2+}$ and a high concentration of $\mathrm{Mg}^{2+}$. The low-Ca ${ }^{2+} /$ high- $\mathrm{Mg}^{2+}$ media antagonized the effect of cholera toxin; however, expression of Fos immunoreactivity was induced in the nuclei of a small number of enteric ncurons simply by exposure to this medium alone. When sacs were incubated in low- $\mathrm{Ca}^{2+} / \mathrm{high}-\mathrm{Mg}^{2+}$ media, the presence of intraluminal cholera toxin did not cause the number of neurons expressing Fos immunoreactivity to increase above that seen in its absence.

\section{Identification of neurons activated by intraluminal cholera toxin}

Double label immunocytochemistry was used to identify neurons in which Fos immunoreactivity was induced by intraluminal cholera toxin. Since colchicine has previously been demonstrated to activate enteric neurons (Kirchgessner et al., 1990), we used antibodies to peptides that can demonstrate immunoreactive nerve cell bodies in material that is not treated with colchicine. Small intestinal sacs were filled with a solution con- 


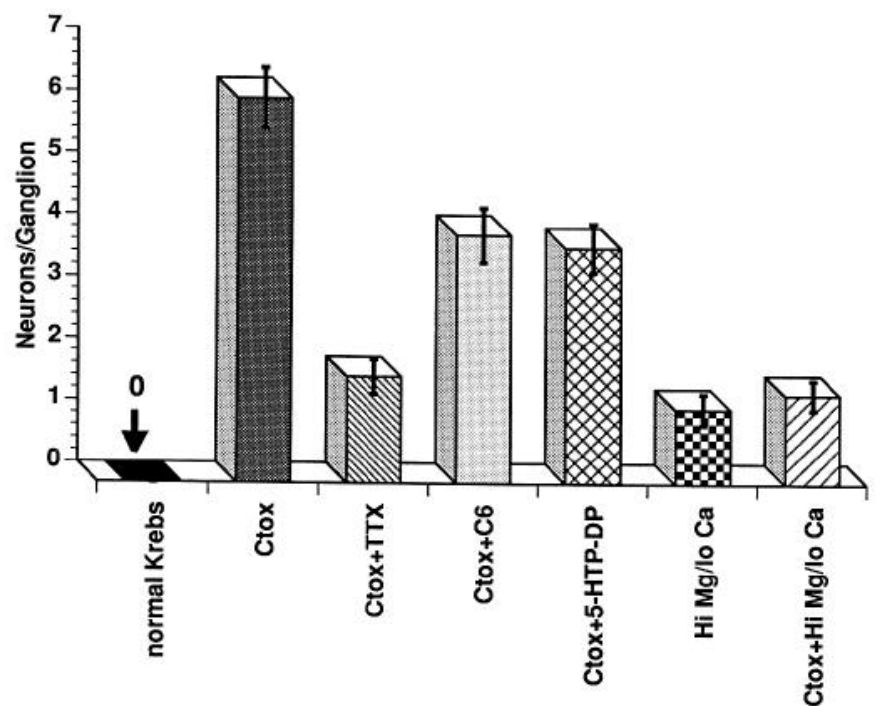

Figure 2. Quantification of nuclear Fos immunoreactivity in submucosal ganglia. The numbers of Fos-immunoreactive neurons/ganglion $\pm \mathrm{SE}$ are shown in control preparations and after the intraluminal application of cholera toxin (Ctox) under a variety of conditions. A 2 $\mathrm{cm}^{2}$ region of each tissue was analyzed. This region was divided into 1 $\mathrm{mm}$ squares. All of the ganglia in every square were examined. The numbers of Fos-immunoreactive cells were determined and expressed as Fos-immunoreactive neurons/ganglion. The cholera toxin-induced increase in expression of Fos immunoreactivity in the nuclei of submucosal ganglion cells is significantly reduced by TTX, hexamethonium (C6), 5-HTP-DP, or incubation in a buffer that contains a high concentration of $\mathrm{Mg}^{2+}$ and a low concentration of $\mathrm{Ca}^{2+}(p<0.001)$. After incubation in a high- $\mathrm{Mg}^{2+} / \mathrm{low}-\mathrm{Ca}^{2+}$ buffer, the nuclei of some submucosal neurons become Fos immunoreactive; however, mucosal application of cholera toxin induces no further increase in Fos immunoreactivity when segments of bowel are incubated in this medium.

taining cholera toxin and incubated as above. Fos immunoreactivity was found to be induced in the nuclei of submucosal neurons that exhibited calbindin immunoreactivity (Fig. 4A). In contrast, none of the myenteric calbindin-immunoreactive neurons in the same preparations exhibited Fos immunoreactivity (Fig. $4 B$ ). Even in those preparations in which doubly labeled neurons were found, most of the Fos-immunoreactive neurons were not immunostained by the antibodies to calbindin. A small subset of submucosal neurons that were DYN immunoreactive were also Fos immunoreactive (Fig. $4 C$ ). Most submucosal DYN-immunoreactive neurons (Fig. 4D), however, and all of those in the myenteric plexus failed to exhibit Fos immunoreactivity. Fos expression was not observed in any submucosal or myenteric neurons that contained NPY or CGRP immunoreactivities (Fig. $4 E, F$ ).

\section{Effects of mucosal deformation on the expression of Fos by enteric neurons}

In order to gain insight into the identification of primary afferent neurons in the bowel, neurons becoming active as a result of the application of a stimulus that is capable of inducing the peristaltic reflex were located. Peristaltic reflexes can be initiated by mechanical distension of the intestinal mucosa (Trendelenburg, 1917; Bülbring and Lin, 1958; Kosterlitz and Lees, 1964; Gershon, 1981; Furness and Costa, 1987). Pressure was applied to the mucosal surface of an opened segment of gut by delivering puffs of $\mathrm{N}_{2}$ from the tip of a micropipette positioned above the
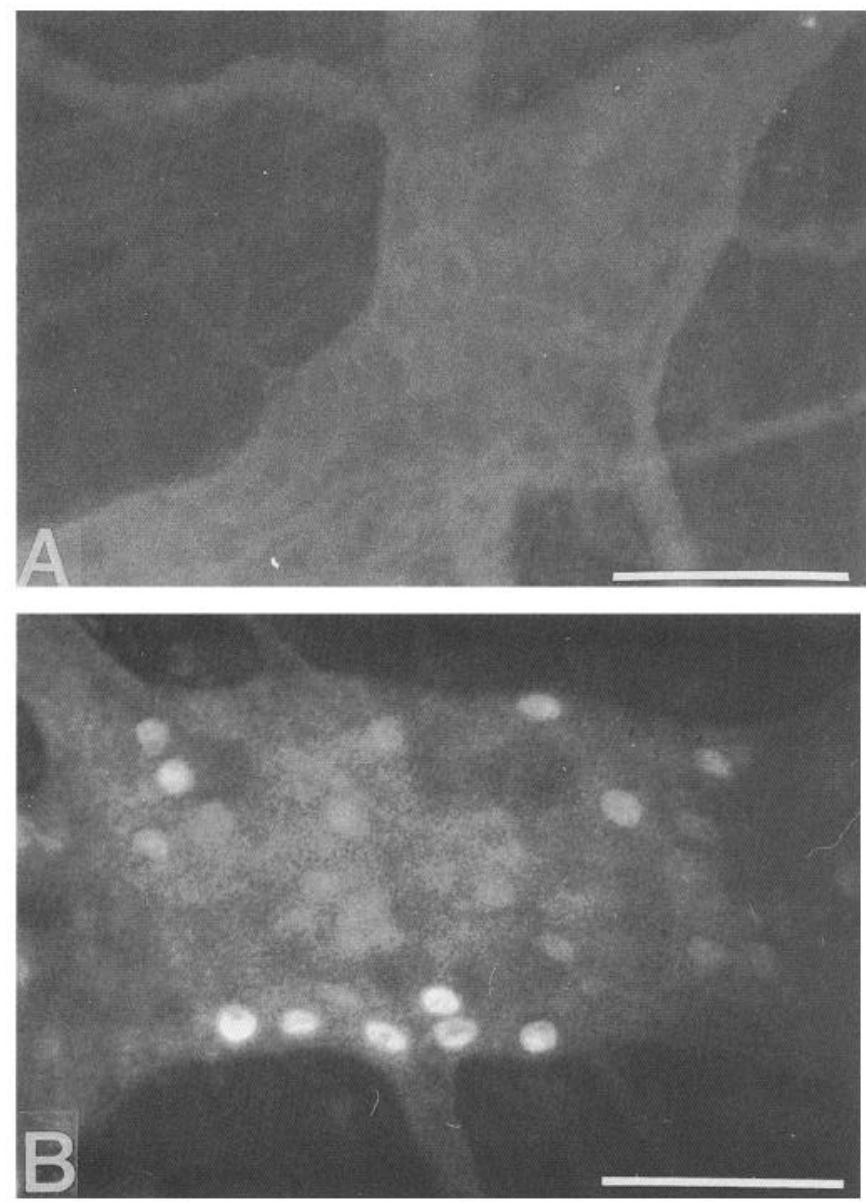

Figure 3. TTX prevents the cholera toxin-induced expression of Fos immunoreactivity in the nuclei of myenteric ganglion cells ( $A$; compare with Fig. $1 D$ ). Hexamethonium decreases the number of neurons in which nuclear Fos immunoreactivity can be seen $(B$; compare with Fig. $1 D$ ). Scale bars, $50 \mu \mathrm{m}$.

intestinal epithelium. This method permitted the intensity of the stimulus to be controlled and its effective area to be restricted. As was true of small intestine removed directly from the animals or incubated for $3 \mathrm{hr}$ as a closed sac in vitro, the opened bowel exhibited no neuronal Fos immunoreactivity when it was incubated for $1 \mathrm{hr}$ in the absence of applied stimuli (see Fig. 6). On the other hand, if puffs of $\mathrm{N}_{2}$ were directed at the mucosa, Fos immunoreactivity was observed in the vicinity of the stimulated region in the nuclei of both submucosal and myenteric neurons (Figs. $5 A, B ; 6$ ). Induction of Fos immunoreactivity was completely prevented in both submucosal (Fig. 6) and myenteric plexuses by addition of TTX $(1.0 \mu \mathrm{M})$. Induction of Fos immunoreactivity was also significantly inhibited by hexamethonium $(10.0 \mu \mathrm{M})$. In the submucosal plexus (Fig. 6), hexamethonium antagonized the spread of Fos immunoreactivity from the region immediately beneath the region of the stimulus to more distant regions of the plexus. In contrast, hexamethonium completely prevented induction of Fos immunoreactivity in the nuclei of myenteric neurons (data not illustrated). Like TTX, 5-HTP-DP $(10 \mu \mathrm{M})$ totally blocked deformation-induced expression of Fos immunoreactivity in both plexuses (Fig. 6). 

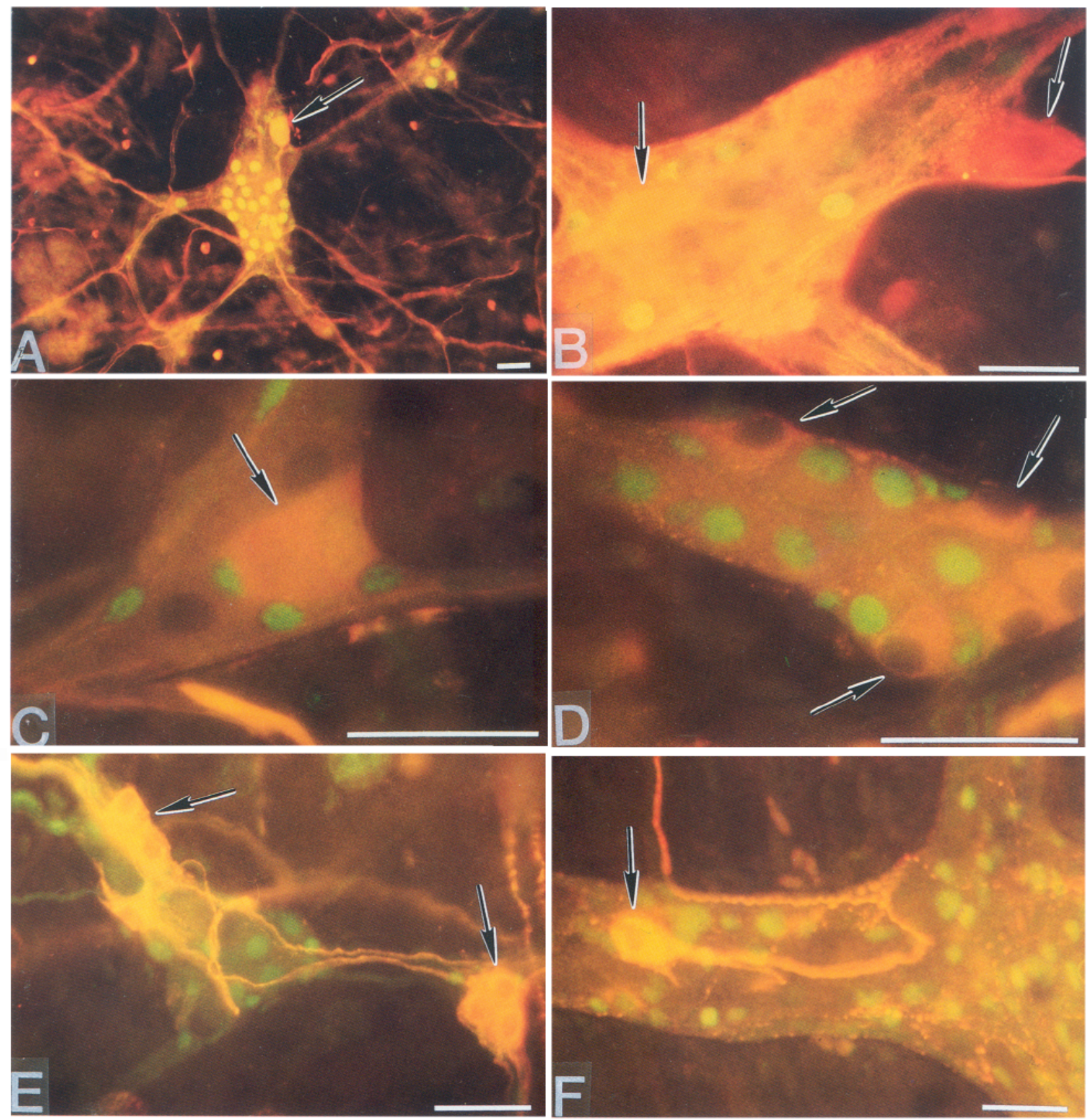

Figure 4. Identification of neurons that display nuclear Fos immunoreactivity following intraluminal application of cholera toxin by double label immunocytochemistry. Fos immunoreactivity has been demonstrated with a secondary antibody labeled with FITC, and the immunoreactivity of a neuropeptide has been visualized with TRITC. Each panel is a double exposure photographed first with the filter/dichroic mirror set for FITC fluorescence, and then with the filter/dichroic mirror set for TRITC fluorescence. $A$, A submucosal ganglion in which Fos and calbindin immunoreactivities are visualized simultaneously. A calbindin-immunoreactive neuron is doubly labeled $(\rightarrow ;$ the nucleus appears yellow). B, In contrast to the submucosal plexus, in the myenteric plexus calbindin-immunoreactive neurons $(\rightarrow)$ do not display Fos immunoreactivity. $C$ and $D$, Submucosal ganglia in which Fos and DYN immunoreactivities are visualized simultaneously. A DYN-immunoreactive neuron $(\rightarrow)$ is doubly labeled $(C)$; however, most DYN-immunoreactive neurons $(\rightarrow)$ do not display nuclear Fos immunoreactivity $(D) . E$ and $F$, NPY-immunoreactive neurons $(\rightarrow)$ fail to display nuclear Fos immunoreactivity in either the submucosal $(E)$ or the myenteric plexus $(F)$. Scale bars, $50 \mu \mathrm{m}$.

Projections of submucosal neurons that exhibit deformation-induced expression of Fos immunoreactivity

Segments of small intestine were opened and the mucosal surface was stimulated with $\mathrm{N}_{2}$ puffs delivered from a micropipette as described above. Retrograde transport was then used to trace the projections of submucosal neurons in which deformationinduced expression of Fos immunoreactivity had been induced (Kirchgessner and Gershon, 1988). FluoroGold was injected with a micropipette into single ganglia of the myenteric plexus in vitro. Three hours were alotted for retrograde transport, after which the preparations were fixed for immunocytochemical and microscopic analysis. The myenteric plexus was examined first 

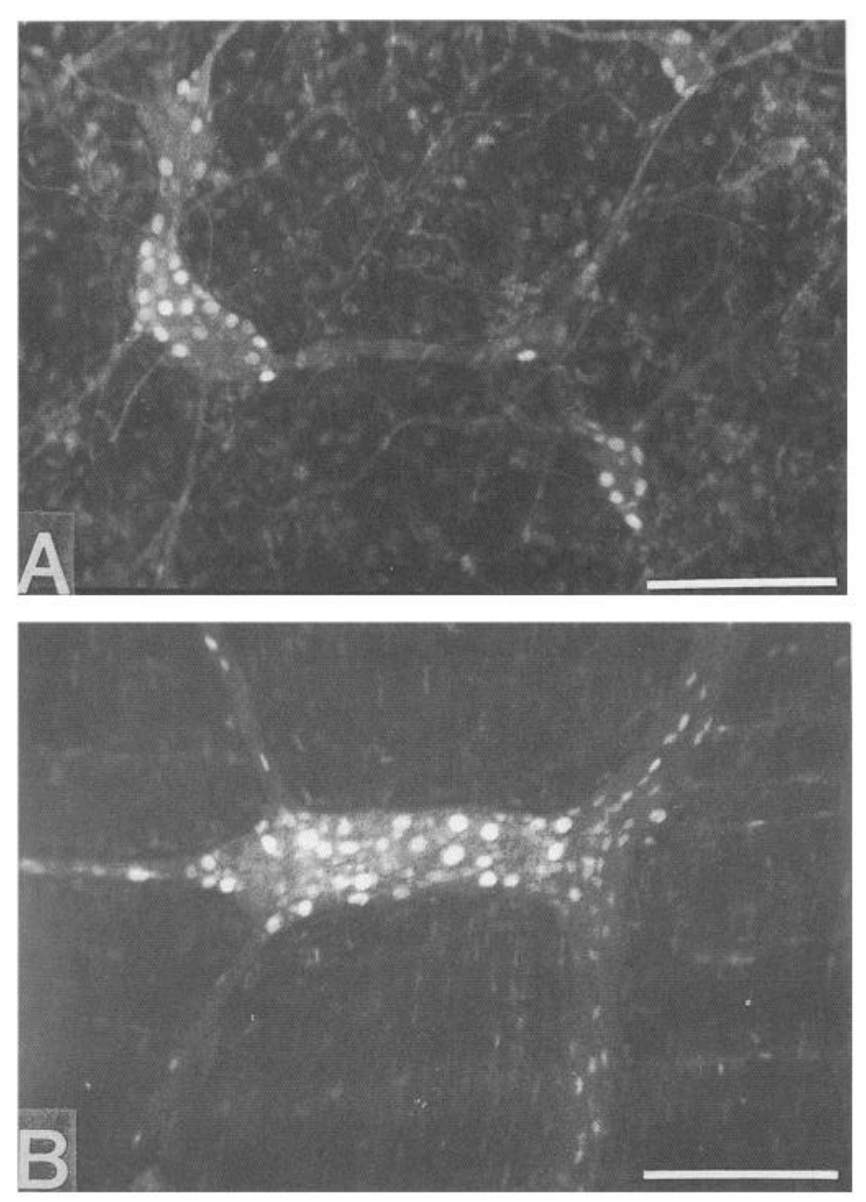

Figure 5. Mucosal deformation induces the expression of Fos immunoreactivity in nuclei of the submucosal $(A)$ and myenteric plexuses (B). Scale bars, $50 \mu \mathrm{m}$.

to confirm that injection sites were limited to a single ganglion (Fig. $7 \mathrm{~A}$ ) and that neurons in distant ganglia had become labeled by retrograde transport (Fig. $7 B$ ). Fos immunoreactivity was then demonstrated in dissected whole-mounts containing the submucosal plexus. The nuclei of submucosal neurons, which contained FluoroGold and thus projected to the myenteric plexus, were observed to be Fos immunoreactive (Fig. $7 C, D$ ). This experiment was repeated in the presence of hexamethonium in order to determine whether the Fos-immunoreactive neurons that projected to the myenteric plexus were excited secondarily via nicotinic synapses. Hexamethonium did not prevent the appearance of deformation-induced Fos immunoreactivity in the nuclei of FluoroGold-labeled submucosal neurons.

Further studies were done to identify neurochemically the neurons in the submucosal plexus that were labeled by retrograde transport of FluoroGold from myenteric ganglia. Both calbindin (Fig. $8 A, B$ ) and substance $\mathrm{P}$ (Fig. $8 C, D$ ) immunoreactivities were studied, and each of these markers was found in FluoroGold-fluorescent submucosal neurons. Colocalization was also observed between calbindin and substance $\mathrm{P}$ immunoreactivities (Fig. 9A,B). Many calbindin/substance P-immunoreactive fibers were also found that left the plane of the submucosal plexus and ran in the direction of the myenteric plexus (Fig. $9 C, D$ ). These fibers appeared to have been cut when the submucosal plexus was dissected away from the deeper lay-

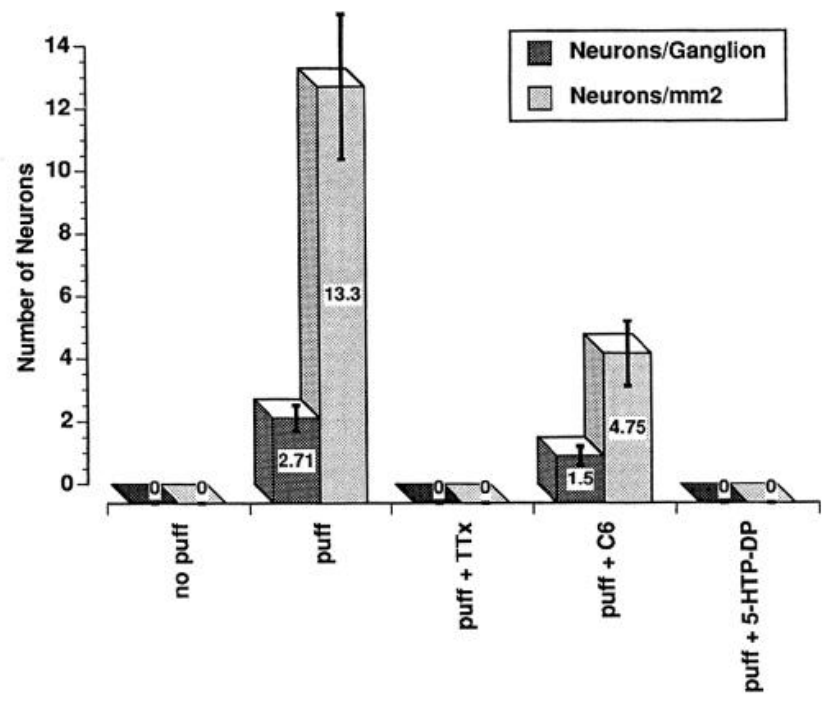

Figure 6. Quantification of nuclear Fos immunoreactivity in submucosal ganglia in relation to mucosal deformation. A $2 \mathrm{~cm}^{2}$ region of each tissue was analyzed. This region was divided into $1 \mathrm{~mm}$ squares. All of the ganglia in every square were examined. The numbers of Fosimmunoreactive cells were determined as described in the caption for Figure 2. Data are presented as Fos-immunoreactive neurons/ganglion $\pm \mathrm{SE}$ and as Fos-immunoreactive neurons $/ \mathrm{mm}^{2} \pm \mathrm{SE}$ of submucosal area. When no puffs of $\mathrm{N}_{2}$ were directed at the mucosa, no neurons displayed nuclear Fos immunoreactivity. Following stimulation with puffs of $\mathrm{N}_{2}$, nuclear Fos immunoreactivity appeared. This effect was abolished by TTX and by 5-HTP-DP. In contrast, hexamethonium ( $C 6)$ did not prevent the induction of nuclear Fos immunoreactivity but significantly reduced its spread. This effect of hexamethonium significantly decreased the numbers of Fos-immunoreactive neurons in the submucosal plexus.

ers of the wall of the bowel. Calbindin-immunoreactive neurons were about $10 \%$ of the total neurons of the submucosal plexus and were not homogeneously distributed. Following myenteric injection of FluoroGold, many calbindin-immunoreactive neurons in ganglia outside the injection site and that were oral and circumferential to the injected ganglion became labeled with FluoroGold (Fig. 9E,F). This observation indicates that calbindin-immunoreactive myenteric neurons project extensively to other ganglia within the myenteric plexus and that most, if not all, of these projections are directed distally and circumferentially. When preparations were subjected to mucosal stimulation with puffs of $\mathrm{N}_{2}$ prior to examination, Fos immunoreactivity was found to be expressed in the nuclei of calbindin-immunoreactive submucosal neurons (Fig. 10A). In contrast, no nuclei of submucosal DYN-, CGRP-, or NPY-immunoreactive neurons (Fig. $10 B, C$ ) and no nuclei of myenteric calbindin-immunoreactive neurons were found to be Fos immunoreactive in these stimulated preparations (Fig. $10 D$ ). Since the $5-\mathrm{HT}_{1 \mathrm{P}}$ receptor antagonist 5-HTP-DP was found to eliminate deformation-induced expression of Fos immunoreactivity in both plexuses, it would be predicted that $5-\mathrm{HT}_{1 \mathrm{P}}$ receptors are present on the primary afferent neurons activated by mucosal puffs of $\mathrm{N}_{2}$. The observation that submucosal calbindin-immunoreactive neurons express nuclear Fos immunoreactivity following stimulation of the gut with mucosal puffs of $\mathrm{N}_{2}$ is consistent with the hypothesis that these are primary afferent neurons. We therefore utilized an anti-idiotypic antibody that recognizes $5-\mathrm{cHT}_{1 \mathrm{P}}$ receptors in the bowel (Kirchgessner et al., 1990, Wade et al., 1990; Tamir et al., 1991) to determine if these receptors 

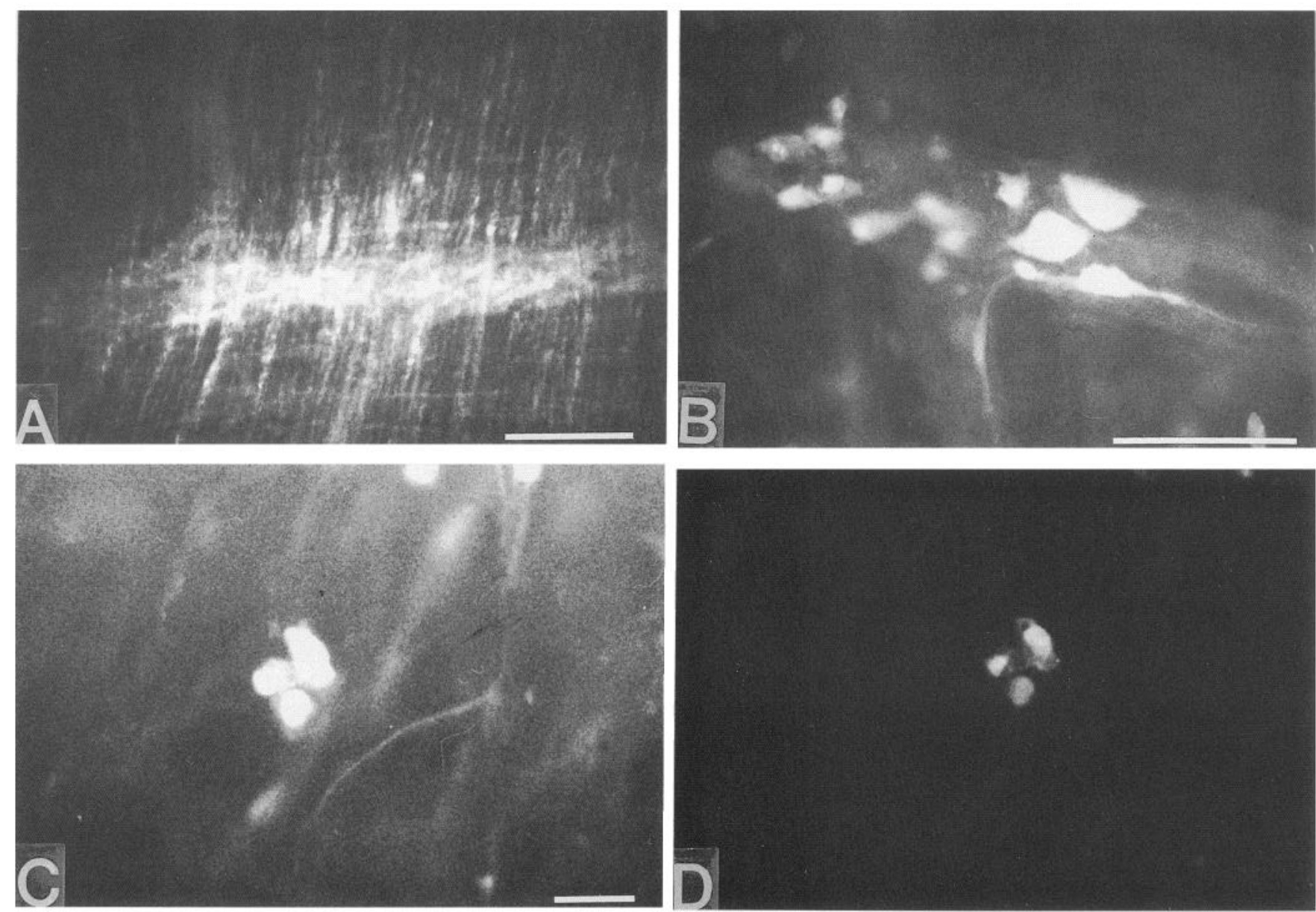

Figure 7. Submucosal neurons in which Fos immunoreactivity is induced by mucosal deformation project to the myenteric plexus. Single ganglia of the myenteric plexus were injected with FluoroGold in order to prelabel submucosal neurons that project to the myenteric plexus by retrograde axonal transport. Puffs of $\mathrm{N}_{2}$ were then directed at the mucosa. A, An injection site in the myenteric plexus. Note that FluoroGold fills a ganglion. $B$, A myenteric ganglion situated $\sim 1 \mathrm{~mm}$ oral to the injection site contains neurons labeled by retrograde transport of FluoroGold. $C$, A submucosal ganglion from the same preparation shown in $A$ and $B$ contains neurons labeled by retrograde transport of FluoroGold. $D$, The same ganglion visualized in $C$, but with the dichroic mirror/filter set for the visualization of the FITC fluorescence indicative of Fos immunoreactivity. The neurons of this ganglion are doubly labeled; therefore, submucosal neurons in which nuclear Fos immunoreactivity is induced by mucosal deformation project to the myenteric plexus. Scale bars: $A$ and $B, 50 \mu \mathrm{m} ; C$ and $D, 30 \mu \mathrm{m}$.

are present on submucosal calbindin-immunoreactive neurons. For this purpose, dissected whole-mounts of the submucosa were processed for the dual immunolocalization of calbindin and 5-HT receptors. 5-HT receptor immunoreactivity was found on the cell bodies and processes of all submucosal calbindinimmunoreactive neurons (Fig. 11A,B). Many submucosal neurons that did not express calbindin immunoreactivity also bound the anti-idiotypic antibodies.

\section{Discussion}

Nuclear expression of Fos immunoreactivity was used to analyze activation of neurons in the enteric plexuses. The absence of nuclear Fos immunoreactivity in neurons in segments of bowel fixed immediately upon removal from the animals, and its similar absence from neurons in sacs of gut incubated for up to $3 \mathrm{hr}$ in vitro, made it possible to use Fos immunoreactivity to assess the effects of experimental procedures on neuronal activity. Two quite different types of stimulus were applied to the wall of the gut. Cholera toxin, a major nonphysiological insult, which was intended to provoke secretion as well as increased motility, was instilled into the lumen of sacs of bowel.
Pulses of $\mathrm{N}_{2}$ were directed at the mucosal surface to evoke the peristaltic reflex more physiologically. Each of these stimuli was found to induce the expression of Fos immunoreactivity in the nuclei of neurons of both the submucosal and myenteric plexuses. Since the nuclear expression of Fos immunoreactivity in response either to cholera toxin or to mucosal puffs of $\mathrm{N}_{2}$ was antagonized by TTX, it is apparent that the activation of $c$-fos is linked to neuronal activity; however, TTX completely prevented Fos expression in response to mucosal puffs of $\mathrm{N}_{2}$ but failed to prevent a small number of neurons in each plexus from expressing nuclear Fos immunoreactivity in preparations exposed to cholera toxin. It is possible that this persistence of $c$-fos activation in response to a very strong stimulus, cholera toxin, occurs because the ENS contains neurons in which the action potential current is carried in part by $\mathrm{Ca}^{2+}$ and is thus TTX resistant (Wood, 1987). Similarly, it should be noted that expression of Fos immunoreactivity was induced in the nuclei of some enteric neurons simply by incubating the bowel in low$\mathrm{Ca}^{2+} / \mathrm{high}-\mathrm{Mg}^{2+}$ media. A subset of enteric neurons is characterized by a very pronounced $\mathrm{Ca}^{2+}$-activated $\mathrm{K}^{+}$conductance (Wood, 1987). These neurons, called AH/type 2 ( $\mathrm{AH}=$ after- 

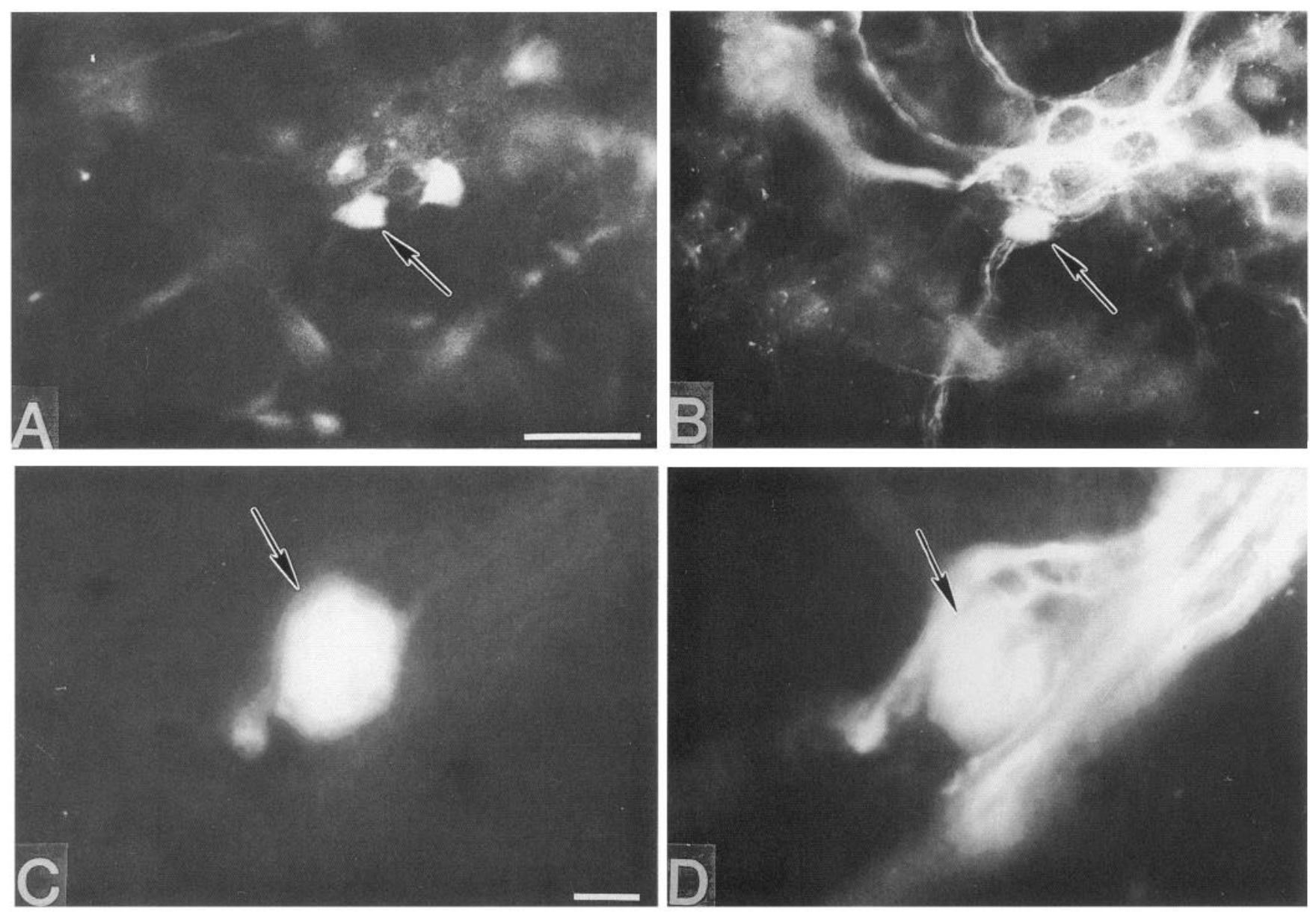

Figure 8. Submucosal neurons that project to the myenteric plexus contain calbindin and substance P. Single ganglia of the myenteric plexus were injected with FluoroGold in order to identify submucosal neurons that project to the myenteric plexus by retrograde axonal transport. $A$, FluoroGold. $B$, The same field as shown in $A$, but with the dichroic mirror/filter setting set for the visualization of calbindin immunoreactivity with FITC. A doubly labeled neuron is indicated $(\rightarrow)$. $C$, FluoroGold. $D$, The same field as shown in $C$, but with the dichroic mirror/filter setting set for the visualization of substance P immunoreactivity with FITC. A doubly labeled neuron is indicated $(\rightarrow)$. Scale bars: $A$ and $B, 50 \mu \mathrm{m} ; C$ and $D, 10 \mu \mathrm{m}$.

hyperpolarization) cells, are known to be excited in low $\mathrm{Ca}^{2+}$. containing solutions because they become depolarized in the absence of the $\mathrm{Ca}^{2+}$-activated $\mathrm{K}^{+}$conductance.

Some of the neurons activated either by cholera toxin or by mucosal puffs of $\mathrm{N}_{2}$ were clearly excited secondarily as a result of cholinergic (nicotinic) synaptic transmission. As a result, the spread of neuronal activation was inhibited by hexamethonium. Within the submucosal plexus, interganglionic transmission is thought to be cholinergic (Surprenant, 1984). If so, then it would follow that the subset of neurons that becomes Fos immunoreactive, despite the presence of hexamethonium, must be activated by sensory receptors that respond to the stimuli, or by the stimuli themselves. In either case, such cells would probably be intrinsic primary afferent neurons. When mucosal puffs of $\mathrm{N}_{2}$ were used as the stimulus, hexamethonium completely prevented the appearance of Fos immunoreactivity in the nuclei of myenteric neurons. This observation implies that none of the primary afferent neurons responsible for detection of mucosal puffs of $\mathrm{N}_{2}$ are located in the myenteric plexus. Spread of excitation from the submucosal plexus, where the primary afferent neurons would have to be located, to the myenteric plexus would appear to be entirely dependent on a cholinergic submucosal to myenteric pathway. Both anterograde and retrograde tracing studies have indicated that a subset of submucosal neurons does indeed project to the myenteric plexus (Kirchgessner and Gershon, 1988). Moreover, when we injected single myenteric ganglia with FluoroGold and then applied mucosal puffs of $\mathrm{N}_{2}$, the submucosal neurons that became labeled by retrograde transport also expressed nuclear Fos immunoreactivity. Double labeling by FluoroGold and Fos immunoreactivity was not prevented by the addition of hexamethonium. The enteric pathways, the existence of which are suggested by these data, are shown diagramatically in Figure 12. Our observations imply that the neurons in the submucosal plexus that become excited in the presence of hexamethonium (and thus are likely to be primary afferents) send cholinergic axons to myenteric ganglia. These submucosal to myenteric projections would explain the ability of stimuli that deform the mucosa of the bowel to elicit the peristaltic reflex, which depends on the activity of myenteric neurons, even if these stimuli fail to excite directly any neurons in the myenteric plexus itself.

On the basis of immunocytochemical studies in combination with myectomies in which regions of the myenteric plexus are ablated in vivo, Bornstein et al. (1989) have suggested that the submucosal neurons that project to the myenteric plexus are likely to be cholinergic cells that costore substance $P$. This group 

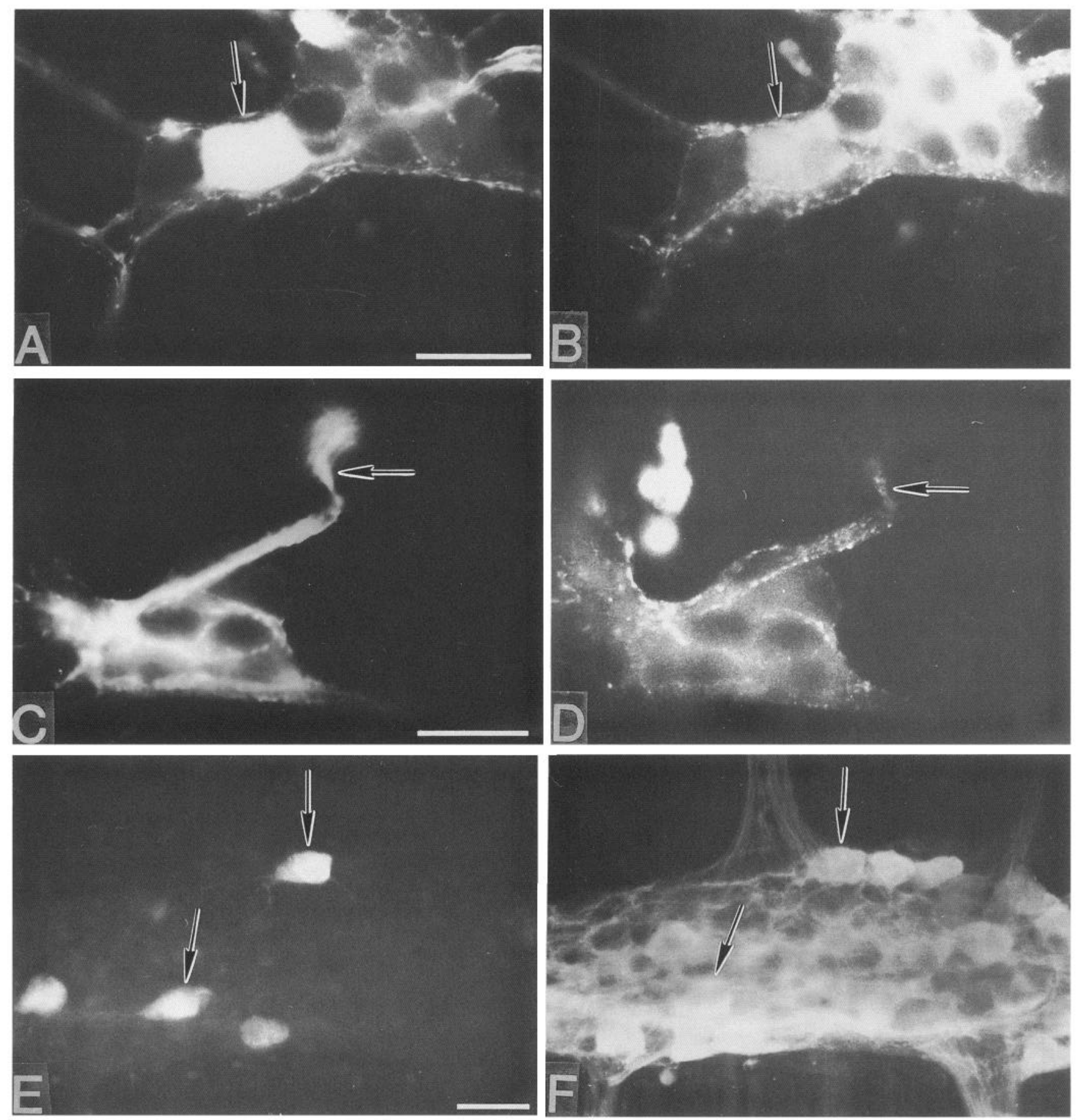

Figure 9. Calbindin and substance $\mathrm{P}$ immunoreactivities are colocalized in neurons of the submucosal plexus. $A$, A submucosal ganglion in which calbindin immunoreactivity is visualized with TRITC. $B$, The same ganglion as shown in $A$, but with the dichroic mirror/filter setting set for the visualization of substance $\mathrm{P}$ immunoreactivity with FITC. A doubly labeled neuron is indicated $(\rightarrow)$. $C$, A submucosal ganglion in which calbindin immunoreactivity is visualized with TRITC. A nerve bundle containing calbindin-immunoreactive fibers $(\rightarrow)$ appears to leave the plane of the plexus and to have been cut during the dissection of the preparation. This appearance suggests that calbindin-immunoreactive fibers are present in interplexus connectives. $D$, The same ganglion as shown in $C$, but with the dichroic mirror/filter setting set for the visualization of substance $\mathrm{P}$ immunoreactivity with FITC. The putative interplexus connective visualized in $C$ contains substance P-immunoreactive axons $(\rightarrow)$. $E$, FluoroGold was injected into a single ganglion of the myenteric plexus. A ganglion located $\sim 2 \mathrm{~mm}$ oral and circumferential to the injected ganglion contains four neurons labeled by retrograde axonal transport. $F$, The same field as shown in $F$, but with the dichroic mirror/filter setting set for the visualization of calbindin immunoreactivity with TRITC. Doubly labeled neurons are indicated $(\rightarrow)$. Scale bars, $50 \mu \mathrm{m}$.

of cells is estimated to constitute about $11 \%$ of all of the neurons of the submucosal plexus (Furness et al., 1984). The supposition that the submucosal neurons that project to the myenteric plexus are cholinergic is consistent with our observation that hexa- methonium prevents induction of Fos immunoreactivity in the nuclei of myenteric, but not submucosal, neurons. Our observations also indicate, however, that at least some of the submucosal neurons that become doubly labeled following mucosal 


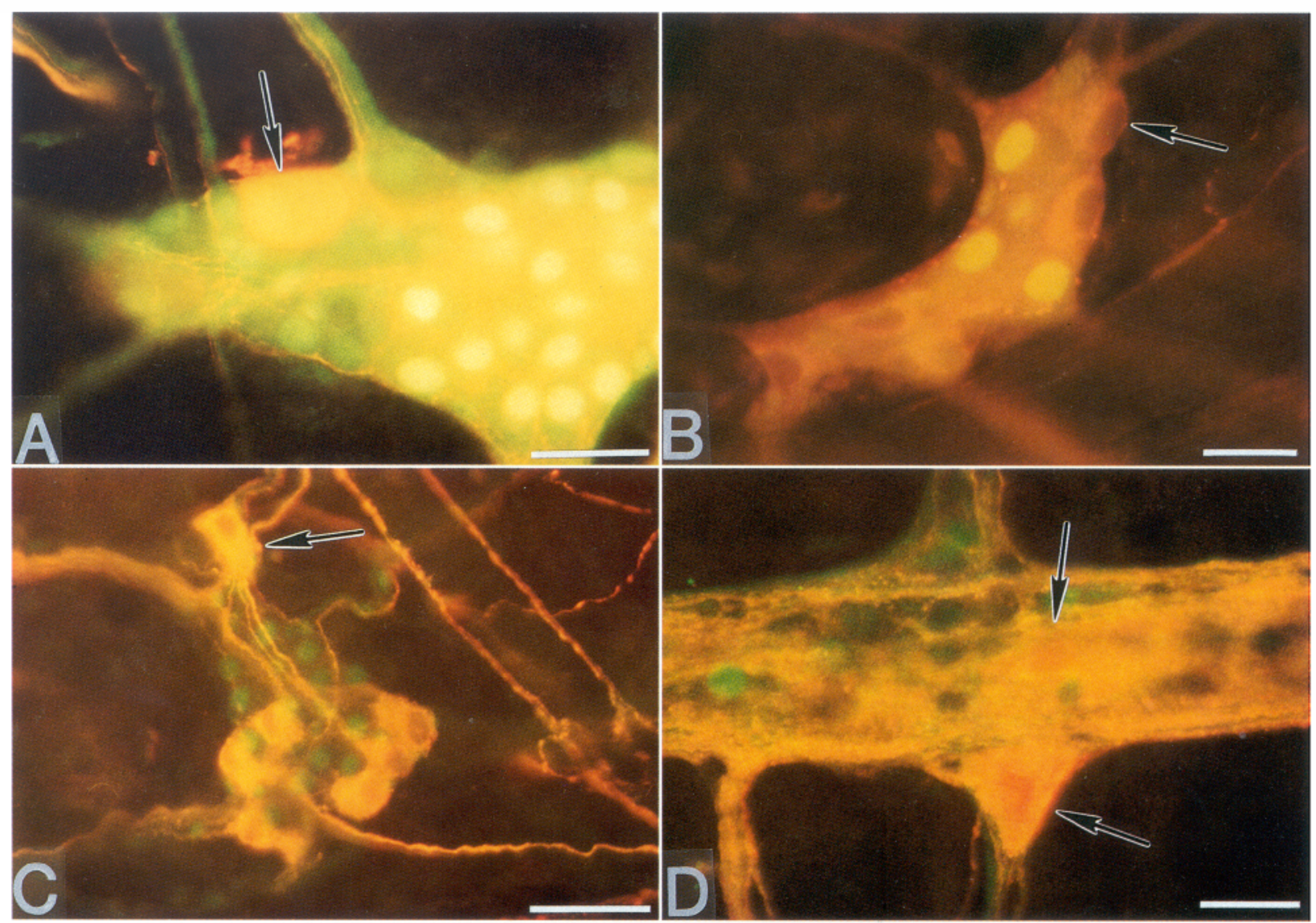

Figure 10. Identification by double label immunocytochemistry of neurons that display nuclear Fos immunoreactivity following mucosal deformation with puffs of $\mathrm{N}_{2}$. Fos immunoreactivity has been demonstrated with a secondary antibody labeled with FITC, and the immunoreactivity of a neuropeptide has been visualized with TRITC. Each panel is a double exposure photographed first with the filter/dichroic mirror set for FITC fluorescence, and then with the filter/dichroic mirror set for TRITC fluorescence. A, A submucosal ganglion in which Fos and calbindin immunoreactivities are visualized simultaneously. A calbindin-immunoreactive ncuron is doubly labeled $(\rightarrow ;$ the nucleus appears yellow). $B$ and $C$, Submucosal ganglia in which Fos and DYN $(B)$ or NPY $(C)$ immunoreactivities are visualized simultaneously. Neither DYN- nor NPY-immunoreactive neurons are doubly labeled $(\rightarrow)$. $D$, In contrast to the submucosal plexus, in the myenteric plexus calbindin-immunoreactive neurons $(\rightarrow)$ do not display Fos immunoreactivity. Scale bars, $50 \mu \mathrm{m}$.

puffs of $\mathrm{N}_{2}$ by antibodies to Fos and by retrograde transport of FluoroGold from the myenteric plexus are calbindin immunoreactive. Since we also find that calbindin and substance $\mathrm{P}$ immunoreactivities are colocalized in neurons of the submucosal plexus, it seems likely that the neurons excited by mucosal puffs of $\mathrm{N}_{2}$ costore substance P. (Since colchicine treatment, which is necessary for the demonstration of substance P immunoreactivity in enteric neurons, itself stimulates these neurons, it is impossible to investigate directly the conclusion that Fos-immunoreactive neurons contain substance P.) Neurons of the submucosal plexus that expressed Fos, but not calbindin, immunoreactivity in the absence of hexamethonium could not be immunostained with antibodies to DYN, NPY, or CGRP. The DYN-immunoreactive set of guinea pig submucosal neurons has been demonstrated to also contain vasoactive intestinal peptide (VIP) (Furness et al., 1984). NPY and CGRP immunoreactivities coexist in the same set of neurons (Furness et al., 1984, 1985). Both the DYN/VIP and the NPY/CGRP neurons are thought to be secretomotor in function (Bornstein and Furness, 1988). The one set of neurons in the submucosal plexus that is not demonstrated by antibodies to any of the markers used in this study is thought to be cholinergic and to function as interneurons connecting ganglia within the submucosal plex- us. Our observations are thus all consistent with the idea that primary afferent neurons exist in the submucosal plexus; that these neurons contain $\mathrm{ACh}$ as well as peptides, including both calbindin and substance $\mathrm{P}$; and that they project to the myenteric plexus. Cholinergic interneurons also become excited in the absence of hexamethonium, and the stimulation of these neurons is responsible for the spread of activity to submucosal ganglia distant from those directly influenced by the stimulus itself. The failure of the DYN/VIP or NPY/CGRP neurons to become excited following mucosal deformation suggests that the submucosal primary afferent neurons stimulated by mucosal puffs of $\mathrm{N}_{2}$ do not efficiently activate secretomotor pathways within the submucosal plexus.

When cholera toxin was employed to stimulate the gut instead of mucosal puffs of $\mathrm{N}_{2}$, a small number of myenteric neurons were found, even in the presence of hexamethonium, to display nuclear Fos immunoreactivity. These may represent myenteric neurons with mucosal projections that are themselves primary afferents. Alternatively, there may be a noncholinergic submucosal to myenteric projection that has not yet been described. Myenteric neurons that project to the mucosa have been reported (Bornstein et al., 1988). Some of these contain VIP, others NPY, and still others have been observed to contain 

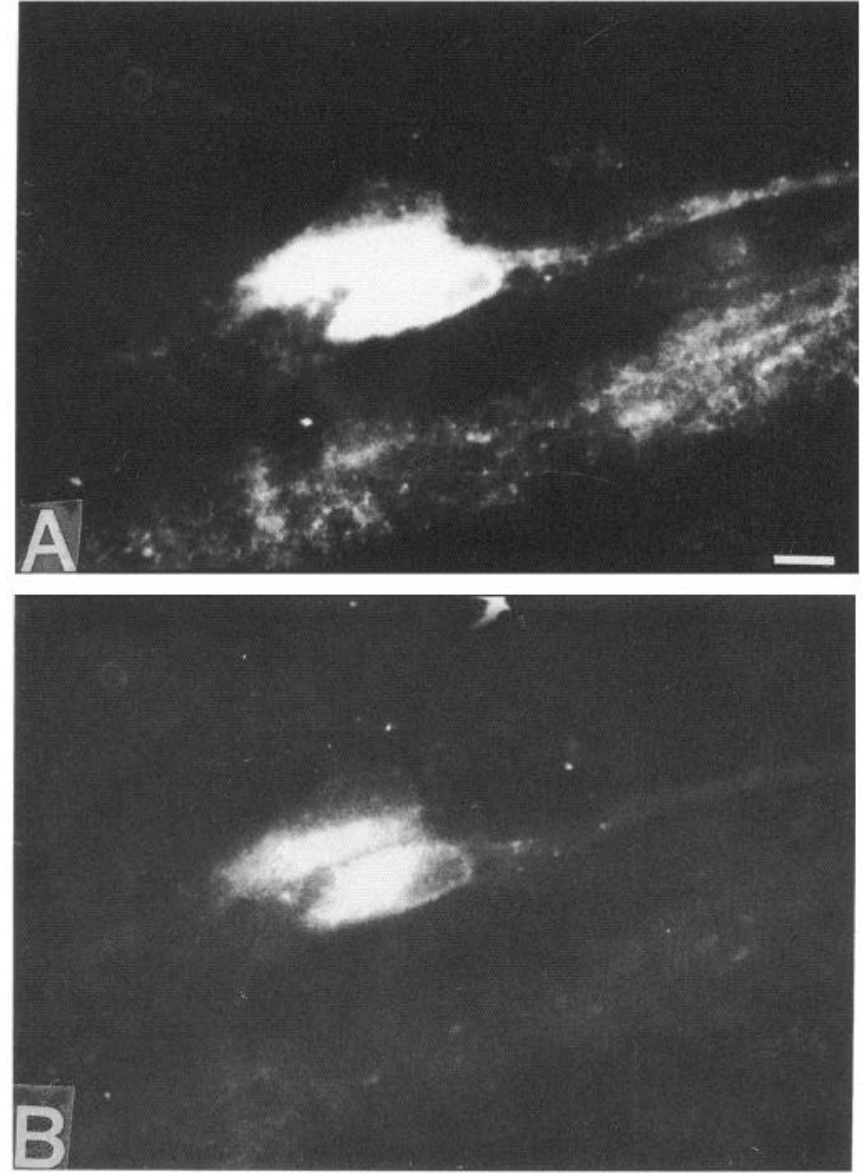

Figure 11. Calbindin-immunoreactive neurons of the submucosal plexus display 5-HT receptors that can be detected with an anti-idiotypic antibody. $A$, A submucosal ganglion in which calbindin immunoreactivity is visualized with TRITC. $B$, The same ganglion as shown in $A$, but with the dichroic mirror/filter setting set for the visualization of the binding of anti-idiotypic antibodies immunoreactivity with FITC. Two doubly labeled neurons can be seen. Scale bar, $10 \mu \mathrm{m}$.

calbindin. In fact, it was the presumed mucosal projections of the myenteric calbindin-immunoreactive neurons, as well as their supposed failure (as AH/type 2 neurons) to receive synaptic input, that led to the speculation that these neurons are the primary afferent neurons of the bowel (Furness et al., 1990). Since none of the myenteric neurons that were induced to express nuclear Fos immunoreactivity were calbindin immunoreactive, our observations fail to provide support for this hypothesis. Within the submucosal plexus, cholera toxin excited many more neurons in the absence of hexamethonium than did mucosal puffs of $\mathrm{N}_{2}$. Some of these neurons were doubly labeled by antibodies to calbindin, suggesting that the primary afferents activated by mucosal deformation were also stimulated by cholera toxin. Additional neurons were induced to become Fos immunoreactive by cholera toxin, which were not immunoreactive when the bowel was stimulated by mucosal puffs of $\mathrm{N}_{2}$. Some of these cholera toxin-excited neurons were DYN immunoreactive, while others were not immunostained by antibodies to DYN, calbindin, NPY, or CGRP. The DYN-immunoreactive neurons, as noted above, are probably secretomotor in function (Bornstein et al., 1988). The neurons that were not doubly labeled by any of the antibodies to peptides used in this study

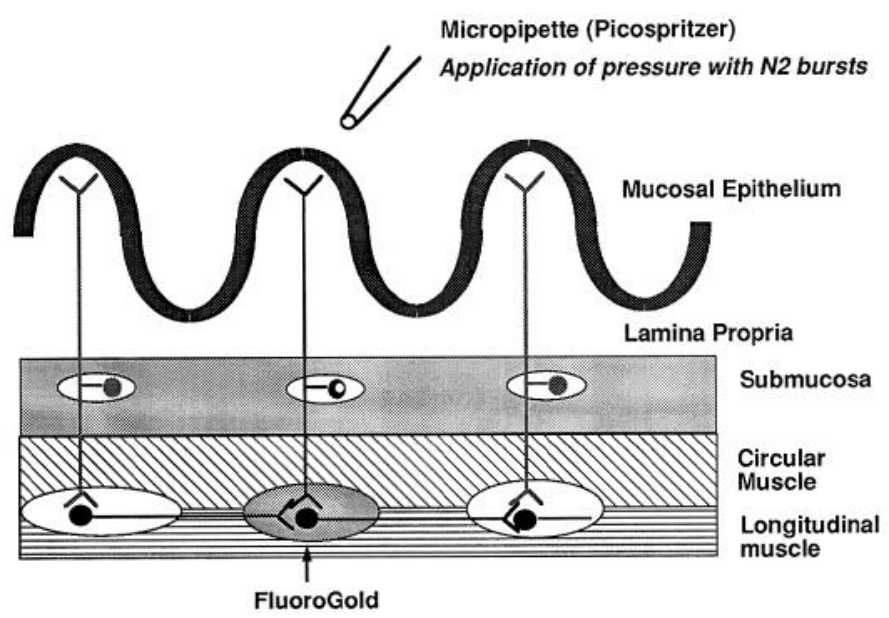

Figure 12. A summary diagram outlining the neural circuits proposed as a result of the current experiments. FluoroGold was injected into a single ganglion of the myenteric plexus (shaded ganglion, center). This injection led to the labeling by retrograde axonal transport of submucosal neurons with terminals in the injected myenteric gangion. Subsequent deformation of the mucosa with puffs of $\mathrm{N}_{2}$ delivered from the tip of a micropipette excited neurons in underlying submucosal ganglia. This excitation was detected by the visualization of nuclear Fos immunoreactivity in the stimulated neurons. The submucosal neurons excited by mucosal deformation to express nuclear Fos immunoreactivity were doubly labeled by retrograde transport of FluoroGold from the myenteric plexus (center ganglion in the submucosal plexus). At least some of these submucosal neurons also contained calbindin and substance $\mathrm{P}$ immunoreactivities and expressed 5-HT receptors detectable with anti-idiotypic antibodies.

were probably the cholinergic interneurons discussed above (Furness et al., 1984). These data are consistent with the view that cholera toxin, like mucosal deformation, excites interneurons; however, the data also indicate that the primary afferent neurons stimulated by cholera toxin activate at least one set of secretomotor neurons that are not stimulated by mucosal puffs of $\mathrm{N}_{2}$. These observations provide support for the hypothesis put forward by Cassuto et al. $(1982,1983)$ that intrinsic enteric nerves contribute to the massive secretory response elicited by applications of cholera toxin to the intestinal mucosa.

In contrast to hexamethonium, the 5- $\mathrm{HT}_{1 \mathrm{P}}$ antagonist 5-HTPDP completely prevented expression of nuclear Fos immunoreactivity in either plexus in response to mucosal puffs of $\mathrm{N}_{2}$. Unlike TTX, 5-HTP-DP does not inhibit nerve conduction; nor does 5-HTP-DP inhibit nicotinic ganglionic transmission (Takaki et al., 1985). In fact, 5-HTP-DP is highly selective. The drug antagonizes the slow depolarizations of myenteric neurons in response to 5-HT but has no action on the similar responses to these cells to ACh (which are muscarinic) or to substance P. The ability of 5-HTP-DP to block the Fos-inducing effects of mucosal puffs of $\mathrm{N}_{2}$ suggests that $5-\mathrm{HT}$ and $5-\mathrm{HT}_{1 \mathrm{P}}$ receptors are involved in mediating the response. Our observation that 5-HT receptor immunoreactivity (demonstrated with anti-idiotypic antibodies) is present on the calbindin-immunoreactive submucosal neurons that express nuclear Fos immunoreactivity provides support for this hypothesis. Exposure of sections treated with the anti-idiotypic antibodies to the $5-\mathrm{HT}_{1 \mathrm{P}}$ antagonist 5-HTP-DP decreases the intensity of immunostaining (Kirchgessner et al., 1990), suggesting that the anti-idiotypic antibodies bind to $5-\mathrm{HT}_{1 \mathrm{P}}$ receptors. The most obvious source of 5-HT for release by mucosal puffs of $\mathrm{N}_{2}$ is the enterochromaffin cell pop- 
ulation of the mucosal epithelium. Enteric neurons also contain 5-HT (Gershon et al., 1989a), but none of the neurons of the submucosal plexus are thought to be serotonergic (Costa et al., 1982). Application of pressure to the mucosa, moreover, has been demonstrated to cause the secretion of 5-HT by enterochromaffin cells (Bülbring and Lin, 1958; Bülbring and Crema, 1959b). An extensive array of 5-HT $\mathrm{H}_{\mathrm{IP}}$ receptors has been detected on nerve fibers in the lamina propria, just beneath the epithelium (Branchek et al., 1988). It thus seems reasonable to propose that mucosal puffs of $\mathrm{N}_{2}$ increase pressure on enterochromaffin cells, which then secrete 5 -HT that activates $5-\mathrm{HT}_{1 \mathrm{P}}$ receptors in the mucosal processes of intrinsic primary afferent neurons (at least some of which are calbindin/substance $P$ immunoreactive and cholinergic). Once activated by 5 -HT, therefore, these cells are able to mediate reflexes by synapsing with other neurons in the submucosal plexus or by synapsing with motor neurons (directly or via interneurons) in the myenteric plexus. When cholera toxin was employed as the stimulus instead of mucosal puffs of $\mathrm{N}_{2}, 5$-HTP-DP diminished the number of neurons of each plexus that expressed Fos immunoreactivity; however, the induction of Fos expression was not fully blocked. This observation is consistent with the hypothesis that cholera toxin activates a greater number of primary afferent neurons than does application of mucosal puffs of $\mathrm{N}_{2}$, and does so by more than one mechanism. 5-HT appears to be involved in the response to cholera toxin (Cassuto et al., 1982, 1983); however, our data suggest that cholera toxin excites enteric neurons by a nonserotonergic mechanism as well. The finding that hexamethonium fully prevented the appearance of Fos immunoreactivity in neurons of the myenteric plexus when the bowel was stimulated with mucosal puffs of $\mathrm{N}_{2}$, but failed to do so when the gut was stimulated with cholera toxin, confirms that a set of neurons is activated by cholera toxin that is not excited by mucosal puffs of $\mathrm{N}_{2}$. Nevertheless, the current observations with mucosal puffs of $\mathrm{N}_{2}$ are consistent with, and supportive of, the hypothesis first put forward by Bülbring and her colleagues that increases in intraluminal pressure evoke the peristaltic reflex through the stimulation of mucosal processes of primary afferent neurons by 5 -HT released from enterochromaffin cells (Bülbring and Lin, 1958; Bülbring and Crema, 1959a). Our evidence that the primary afferent neurons critical to the mediation of responses to mucosal puffs of $\mathrm{N}_{2}$ reside in the submucosal plexus is also consistent with Bülbring's ideas (Bülbring et al., 1958).

\section{References}

Bayliss WM, Starling EH (1899) The movements and innervation of the small intestine. J Physiol (Lond) 24:100-143.

Bayliss WM, Starling EH (1900) The movements and innervation of the small intestine. J Physiol (Lond) 26:125-138.

Bornstein JC, Furness JB (1988) Correlated electrophysiological and histochemical studies of submucous neurons and their contribution to understanding enteric neural circuits. J Auton Nerv Syst 25:1-13.

Bornstein JC, Costa M, Furness JB (1988) Intrinsic and extrinsic inhibitory synaptic inputs to submucous neurones of the guinea-pig small intestine. J Physiol (Lond) 398:371-390.

Bornstein JC, Furness JB, Costa M (1989) An electrophysiological comparison of substance P-immunoreactive neurons and other neurons in the guinea-pig submucous plexus. J Autonom Nerv Syst 26: 113-120.

Branchek T, Mawe G, Gershon MD (1988) Characterization and localization of a peripheral neural 5-hydroxytryptamine receptor subtype with a selective agonist, ${ }^{3} \mathrm{H}-5$-hydroxyindalpine. J Neuro 8:25822595.

Bülbring E, Crema A (1959a) The action of 5-hydroxytryptamine, 5-hydroxytryptophan and reserpine on intestinal peristalsis in anaesthetized guinea-pigs. J Physiol (Lond) 146:29-53.

Bülbring E, Crema A (1959b) The release of 5-hydroxytryptamine in relation to pressure exerted on the intestinal mucosa. J Physiol (Lond) 146:381-407.

Bülbring E, Lin RCY (1958) The effect of intraluminal application of 5-hydroxytryptamine and 5-hydroxytryptophan on peristalsis: the local production of 5-HT and its release in relation to intraluminal pressure and propulsive activity. J Physiol (Lond) 140:381-407.

Bülbring E, Lin RCY, Schofield G (1958) An investigation of the peristaltic reflex in relation to anatomical observations. Q J Exp Physiol 43:26-37.

Cassuto J, Jodal M, Tuttle R, Lundgren O (1982) 5-Hydroxytryptamine and cholera secretion. Scand J Gastroenterol 17:695-703.

Cassuto J, Siewert A, Jodal M, Lundgren O (1983) The involvement of intraluminal nerves in cholera toxin induced intestinal secretion. Acta Physiol Scand 117:195-202.

Clague JR, Sternini C, Brecha N (1985) Localization of calcitonin gene-related peptide-like immunoreactivity in neurons of the rat gastrointestinal tract. Neurosci Lett 56:63-68.

Costa M, Furness JB, Cuello AC, Verhofstad AAJ, Steinbusch HWJ, Elde RP (1982) Neurons with 5-hydroxytryptamine-like immunoreactivity in the enteric nervous system: their visualization and reactions to drug treatment. Neuroscience 7:351-363.

Cuello AC, Galfre G, Milstein C (1979) Detection of substance P in the central nervous system by a monoclonal antibody. Proc Natl Acad Sci USA 76:3532-3536.

Curan T, Morgan JI (1985) Superinduction of $c$-fos by nerve growth factor in the presence of peripherally active benzodiazepines. Science 229:1265-1268.

DiFiglia M, Christakos S, Aronin N (1989) Ultrastructural localization of immunoreactive calbindin- $\mathrm{D}_{28 \mathrm{~K}}$ in the rat and monkey basal ganglia, including subcellular distribution with colloidal gold labeling. $J$ Comp Neurol 279:653-665.

Erde SM, Sherman D, Gershon MD (1985) Morphology and serotonergic innervation of physiologically identified cells of the guineapigs myenteric plexus. J Neurosci 5:617-633.

Furness JB, Costa M (1987) The enteric nervous system. New York: Churchill Livingston.

Furness JB, Costa M, Keast JR (1984) Choline acetyltransferase and peptide immunoreactivity of submucous neurons in the small intestine of the guinea-pig. Cell Tissue Res 237:328-336.

Furness JB, Costa M, Gibbins IL, Llewellyn-Smith IJ, Oliver JR (1985) Neurochemically similar myenteric and submucous neurons directly traced to the mucosa of the small intestine. Cell Tissue Res 241:155163.

Furness JB, Trussell DC, Pompolo S, Bornstein JC, Smith TK (1990a) Calbindin neurons of the guinea-pig small intestine: quantitative analysis of their numbers and projections. Cell Tissue Res 260:261-272.

Gershon MD (1981) The enteric nervous system. Annu Rev Neurosci 4:227-272.

Gershon MD, Mawe GM, Branchek TA (1989a) 5-Hydroxytryptamine and enteric neurons. In: Peripheral actions of 5-hydroxytryptamine (Fozard JR, ed), pp 247-264. New York: Oxford UP.

Gershon MD, Kirchgessner AL, Wade PR (1989b) Involvement of 5-HT and subtypes of 5-HT receptor in the activation of enteric ncurons by intraluminal cholera toxin. Soc Ncurosci Abstr 15:1989.

Hendriks R, Bornstein JC, Furness JB (1990) An electrophysiological study of the projections of putative sensory neurons within the myenteric plexus of the guinea pig ileum. Neurosci Lett 110:286-290.

Hirst GDS, Holman ME, Spence I (1974) Two types of neurones in the myenteric plexus of duodenum in the guinea-pig. J Physiol (Lond) 236:303-326.

Hunt SP, Pini A, Evan G (1987) Induction of $c$-fos-like protein in spinal cord neurons following sensory stimulation. Nature 328:632634.

Iyer V, Bornstein JC, Costa M, Furness JB, Takahashi Y, Iwanaga T (1988) Electrophysiology of guinea-pig myenteric neurons correlated with immunoreactivity for calcium binding proteins. J Auton Nerv Syst 22:141-150.

Ju G, Han Z, Fan L (1989) Fluorogold as a retrograde tracer used in combination with immunohistochemistry. J Neurosci Methods 29: 69-72.

Kirchgessner AL, Gershon MD (1988) Projections of submucosal neurons to the myenteric plexus of the guinea pig intestine: in vitro tracing 
of microcircuits by retrograde and anterograde transport. J Comp Neurol 277:487-498.

Kirchgessner AL, Dodd J, Gershon MD (1988) Markers shared between dorsal root and enteric ganglia. J Comp Neurol 276:607-621.

Kirchgessner AL, Tamir H, Gershon MD (1990) 5-HT receptors on neurons of the bowel and pancreas: a study with anti-idiotypic antibodies and ${ }^{3} \mathrm{H}-5-\mathrm{HT}$. FASEB J 4:4145.

Kosterlitz HW, Lees GM (1964) Pharmacological analysis of intrinsic intestinal reflexes. Pharmacol Rev 16:301-339.

Lees GM, Leishman DJ, Pearson GT (1989) Electrophysiological characteristics of guinea-pig myenteric plexus neurons immunoreactive for dynorphin A(1-8). In: Nerves and the gastrointestinal tract (Singer MV, Goebell H, eds), pp 79-86. Dordrecht, The Netherlands: Kluwer.

Mawe GM, Gershon MD (1989) Structure, afferent innervation, and transmitter content of ganglia of the guinea pig gallbladder: relationship to the enteric nervous system. J Comp Neurol 283:374-390.

Mawe GM, Branchek T, Gershon MD (1986) Peripheral neural serotonin receptors: identification and characterization with specific agonists and antagonists. Proc Natl Acad Sci USA 83:9799-9803.

Menétrey D, Gannon A, Levine JD, Basbaum AI (1989) Expression of $c$-fos protein in interneurons and projection neurons of the rat spinal cord in response to noxious somatic, articular, and visceral stimulation. J Comp Neurol 285:177-195.

Morgan JI, Cohen DR, Hempstead JL, Curan T (1987) Mapping patterns of c-fos expression in the central nervous system after seizure. Science 237:192-196.

Presley RW, Menétrey D, Levine JD, Basbaum AI (1990) Systemic morphine suppresses noxious stimulus-evoked Fos protein-like immunoreactivity in the rat spinal cord. J Neurosci 10:323-335.
Rothman TP, Nilaver G, Gershon MD (1984) Colonization of the developing murine enteric nervous system and subsequent phenotypic expression by the precursors of peptidergic neurons. J Comp Neurol 225:13-23.

Sagar SM, Sharp FR, Curan T (1988) Expression of c-fos protein in brain: metabolic mapping at the cellular level. Science 240:13281331 .

Surprenant A (1984) Two types of neurones lacking synaptic input in the submucous plexus of guinea-pig small intestine. J Physiol (Lond) 351:363-378.

Takaki M, Branchek T, Tamir H, Gershon MD (1985) Specific antagonism of enteric neural serotonin receptors by dipeptides of 5-hydroxytryptophan: evidence that serotonin is a mediatory of slow synaptic excitation in the myenteric plexus. J Neurosci 5:1769-1780:

Tamir HD, Liu K, Hsiung S, Yu PY, Kirchgessner AL, Gershon MD (1991) Identification of serotonin receptors recognized by anti-idiotypic antibodies. J Neurochem, 57:930-942.

Trendelenburg P (1917) Physiologische und pharmakologische Versuche über die Dünndarm Peristaltick. Naunyn Schmiedegbergs Arch Exp Pathol Pharmakol 81:55-129.

Wade PR, Tamir H, Kirchgessner AL, Gershon MD (1990) Use of anti-idiotypic antibodies to study the role of 5-HT receptors in the activation of enteric neurons. Gastroenterology 99:1234.

Wade PR, Mawe GM, Branchek TA, Gershon MD (1991) Use of stereoisomers of zacopride to analyze actions of 5-hydroxytryptamine on enteric neurons. Am J Physiol 260:G80-G90.

Wood JD (1987) Physiology of enteric neurons. In: Physiology of the gastrointestinal tract, Vol 1, 2d ed (Johnson LR, ed), pp 1-41. New York: Raven. 